\title{
The effect of community nurses and health volunteers on child mortality: The Navrongo Community Health and Family Planning Project
}

Brian Wells Pence

Philomena Nyarko

Population Council

James F. Phillips

Population Council

Cornelius Debpuur

Follow this and additional works at: https://knowledgecommons.popcouncil.org/departments_sbsr-pgy

Part of the Demography, Population, and Ecology Commons, Family, Life Course, and Society Commons, Health Policy Commons, International Public Health Commons, and the Maternal and Child Health Commons How does access to this work benefit you? Let us know!

\section{Recommended Citation}

Pence, Brian Wells, Philomena Nyarko, James F. Phillips, and Cornelius Debpuur. 2005. "The effect of community nurses and health volunteers on child mortality: The Navrongo Community Health and Family Planning Project," Policy Research Division Working Paper no. 200. New York: Population Council. Version of record: https://doi.org/10.1080/14034940701349225 


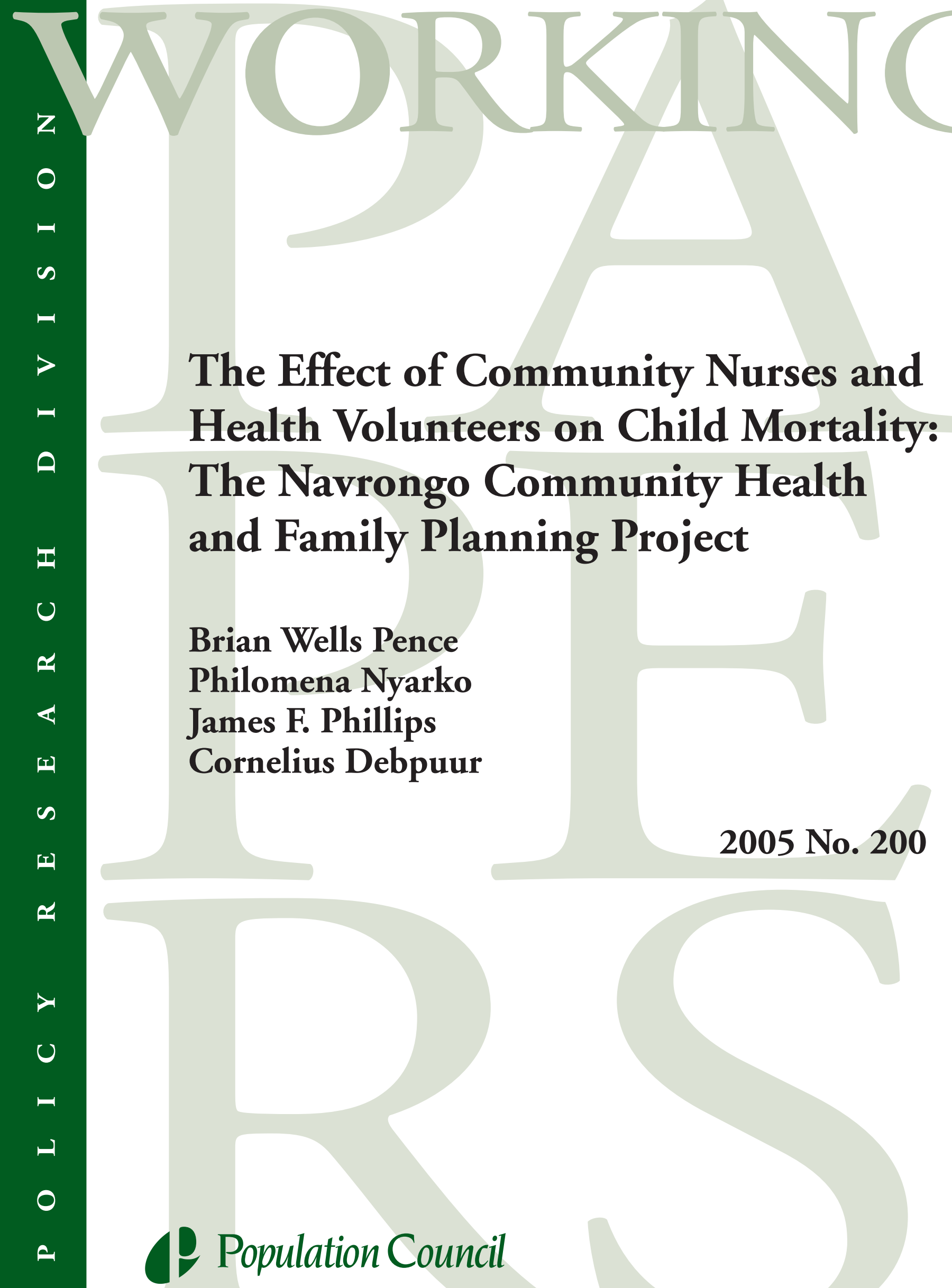




\section{(P) Population Council}

One Dag Hammarskjold Plaza

New York, New York 10017 USA

www.popcouncil.org

pubinfo@popcouncil.org

This material may not be reproduced without written permission from the authors. For a list of Policy Research Division Working Papers, including those that are currently available for downloading in PDF format, see www.popcouncil.org/publications/wp/prd/rdwplist.html.

ISSN: $1554-8538$

(C) 2005 The Population Council, Inc. 


\title{
The Effect of Community Nurses and Health Volunteers on Child Mortality: The Navrongo Community Health and Family Planning Project
}

\author{
Brian Wells Pence, Philomena Nyarko, James F. Phillips, Cornelius Debpuur
}

Brian Wells Pence is Howard Hughes Medical Institute Predoctoral Fellow, Department of Epidemiology, University of North Carolina at Chapel Hill School of Public Health. Philomena Nyarko is Program Officer, Frontiers in Reproductive Health, Population Council, Ghana Office, Accra. James F. Phillips is Senior Associate, Policy Research Division, Population Council. Cornelius Debpuur is Rockefeller Fellow and Principal Investigator, Adolescent Health Project, Navrongo Health Research Centre, Navrongo, Upper East Region, Ghana.

The Navrongo Demographic Surveillance System is funded by the National Institutes of Health, the Rockefeller Foundation, and the United States Agency for International Development. Funding for the contributions of Brian Pence and James Phillips, as well as funding for the Navrongo Community Health and Family Planning Project, was provided by the United States Agency for International Development. Work by Philomena Nyarko and Cornelius Debpuur was funded by grants to the Population Council by the Mellon and Rockefeller Foundations, respectively. The authors gratefully acknowledge the leadership of Fred N. Binka in the design and implementation of the Navrongo Community Health and Family Planning Project as well as his contributions to the preparation of this report. They also express their gratitude to the Navrongo Demographic Surveillance System datacollection and management team. They thank Louise Kuhn for her guidance in preparing an earlier version of this paper. 


\begin{abstract}
This report presents the child mortality impact of a trial of primary health-care servicedelivery strategies in rural Ghana. After adjustment for sociodemographic factors, underfive mortality in areas with village-based community-nurse services fell by 16 percent during the five years of program implementation compared with mortality before the intervention. Reductions were observed in infant ( 6 percent), early child (20 percent), and late child (41 percent) mortality. Community involvement and training of a local health volunteer were associated with an 11 percent increase in mortality, primarily driven by a 124 percent increase in early child mortality. Areas with both nurses and volunteers experienced a 7 percent increase in mortality, with small increases in all age groups. In a comparison area, under-five mortality fell by 5 percent during the same time period. These results suggest that convenient, accessible professional medical care can reduce child mortality in impoverished African settings. They raise questions, however, about the benefits to children's survival of relying on community volunteers.
\end{abstract}


For decades the international community has actively promoted simple and effective health technologies such as vaccines, antibiotics, and oral rehydration salts to address the major causes of child morbidity and mortality in less-developed countries. Despite the low cost and ready availability of these proved health technologies, the World Health Organization's goal of "Health for All by the Year 2000," articulated in 1978 at the International Conference on Primary Health Care held in Alma-Ata, USSR (WHO 1978), remains elusive at the beginning of the twenty-first century in sub-Saharan Africa, where one in every six children dies in the first five years of life (UNICEF 2004). Evidence indicates that supply-side efforts to provide technology and resources for programs are insufficient for achieving "Health for All," and attention to the need for health equity and community involvement in service delivery has increased (World Bank 1994). Inequity and inaccessibility are recognized as key constraints to gains in health, and, as a result, international attention has been directed to achieving community-managed and -sustained primary health care (Gwatkin 1980; Mosley 1985; UNICEF 1986; Berman et al. 1987; Ngom et al. 2001; Gwatkin et al. 2004). The delivery in isolation of proved healthpromoting technologies such as vaccination for measles may result in less than the expected net health benefits as a result of competing risks, a fact that underlines the importance of coordinating and integrating multiple health-promotion efforts and identifying successful organizational strategies for their delivery (WHO 1978; Mosley 1984).

To address the need for practical field trials of organizational strategies for community health-service delivery, the Government of Ghana launched the Navrongo Community Health and Family Planning Project (CHFP) in 1993. The goal of the CHFP is to develop and test feasible strategies for achieving the goals of "Health for All." The CHFP serves a broader international need for rigorous, controlled evaluations of healthservice delivery strategies in impoverished rural sub-Saharan African settings.

The design of the CHFP addresses the observation that two broad sets of underused resources for health programs exist in much of sub-Saharan Africa: (1) trained health providers and supplies in fixed-location clinics that are often inefficiently situated and structured to provide health care to isolated communities, and (2) traditional village-based authorities who can be mobilized to build community support for and involvement in the provision of health services, but who often are ignored by government agencies and programs (Amonoo-Lartson 1981; Knippenberg et al. 1990; World Bank 1994). The CHFP tests the effectiveness of alternative strategies for making use of these resources at the community level. The project operates on the premise that "Health for All" has failed because existing organizational resources for health-service delivery have not been mobilized adequately.

This paper reports on the impact of the CHFP on under-five mortality in the first five years of project implementation.

\section{METHODS}

\section{Setting}

The Navrongo CHFP is being implemented in Kassena-Nankana District in northern Ghana. Total fertility and infant mortality rates in the district are high, educational 
attainment is low, and few households have a toilet or latrine. Measles, malaria, diarrheal disease, and acute respiratory infections are the primary causes of postneonatal and child mortality (Binka et al. 1994, 1995a, and 1995c; Shier et al. 1996; Binka et al. 1997a; Dollimore et al. 1997). The causes of neonatal deaths in the district have not been studied in detail, although delivery complications, low birth weight, and other biological factors are likely the most important causes. Poor harvests due to unpredictable rainfall result in nutritional adversity (NHRC 1998), which acts in synergy with infectious diseases to elevate child mortality (Mosley 1984; Hill and Pebley 1989). Breastfeeding is nearly universal in the region and usually continues well into a child's second or third year, but exclusive breastfeeding commonly ends within the first few weeks, and about three-quarters of children receive solid supplements by the time they are six months old (Nyarko et al. 2003; GSS et al. 2004). HIV-1 seroprevalence is low in Ghana relative to other parts of sub-Saharan Africa. In 2003, 3.1 percent of adults aged 15-49 in Ghana and 3.6 percent of pregnant Ghanaian women seeking antenatal care were estimated to be HIV-positive (GHS 2004; UNAIDS 2004). HIV seroprevalence in Kassena-Nankana District is unknown.

\section{Study Design}

The CHFP is a four-arm community-randomized controlled experiment designed to assess the health and mortality impact of three alternative organizational strategies for community health services compared with standard Ministry of Health (MOH) service provision (see Figure 1). The project design is described in detail in Binka et al. (1995b). The community-mobilization intervention involves traditional village authorities and volunteers in planning and delivering health services. The MOH-mobilization intervention moves trained nurses from fixed-location clinics to village residences and gives them doorstep service-delivery responsibilities. The combined intervention implements both approaches and establishes close links between the MOH nurse and the community leaders and volunteers. A comparison area receives services according to standard $\mathrm{MOH}$ guidelines.

The study region was divided into four geographically distinct areas that corresponded as closely as possible to locally recognized political boundaries (the spheres of influence of village chiefs) and $\mathrm{MOH}$ catchment areas. The three interventions and the comparison condition were then randomly assigned to the four areas.

Initially, primary-health-care and community-outreach training were upgraded in all four areas. This upgrading conformed to existing $\mathrm{MOH}$ plans and did not rely on resources that are unavailable in other parts of Ghana. Community health nurses are the primary service providers for subdistrict and outreach clinics in the Ghana health system. They receive two years of paramedical training for treating common ailments and administering immunizations. In Kassena-Nankana District, they provide care primarily through facilitybased programs with some outreach services for health education and routine immunizations. At the beginning of the CHFP, all 32 nurses in the four areas received a refresher course on health-care delivery, safe delivery, and reproductive health. All nurses were additionally trained in midwifery and methods of community entry, liaison, and outreach. 
The community-mobilization intervention (areas 1 and 3) involves traditional social institutions in health-service delivery and planning. It was specifically designed to represent an operationalization of the Bamako Initiative (Knippenberg et al. 1990), which advocates mobilizing cultural resources such as chieftancy, lineage, and social network systems and training volunteers to deliver basic health care and information. Village health committees were established in collaboration with chiefs, elders, and other key individuals and groups. The committees appoint and oversee a cadre of primarily male health volunteers. Volunteers receive six weeks of initial training and quarterly refresher training sessions. They visit households to talk about hygiene, child immunization, and other health issues, and to make the community aware that they are available for basic treatments and referrals. They are supplied with paracetamol, chloroquine, aludrox, and multivitamins, but they do not carry antibiotics or vaccines. They provide referrals to the clinics and hospital for more complicated services.

The MOH-mobilization intervention (areas 2 and 3) tests the effectiveness of improving access to primary-health-care services. All nurses in this area were reassigned from subdistrict clinics to village residences built by the community and given door-to-door service-delivery responsibilities. They were redesignated as "community health officers." Their supervisors were also trained in community outreach and are charged with regularly visiting the community health officers on-site. The community health officer provides ambulatory care at her residence and visits all compounds in the community in 90-day cycles for health education, follow-up, and diagnosis. The project provides her with a motorbike for community liaison work, and she is responsible for visiting compound heads and organizing immunization and outreach days. She provides referrals to the clinics or hospital for any services she is not able to provide. She does not provide transportation for patients.

Demographic surveillance of the study population began with a census in July 1993. Three villages each in the MOH-mobilization and combined intervention areas served as pilot intervention sites. The first community health officers were deployed in February 1994 and the first volunteers in January 1995. The interventions were scaled up to all villages in the three intervention areas during the period from July 1995 to September 1996.

\section{Data and Methodology}

The Navrongo Demographic Surveillance System (NDSS) has monitored births, deaths, and migrations for all individuals in the study area (population 140,000) since July 1993 (Binka et al. 1997b; Phillips et al. 2000b). A unique permanent personal identification number identifies each individual, permitting the construction of complete residence histories for people who leave and return to the study area. Interviewers visit each compound in the study area in 90-day cycles to update residence registers with demographic events that occurred in the previous three months.

The sample used in this analysis consists of all children in the study area who were younger than five years between 1 July 1993 and 30 April 2000. The data are structured in person-time format, with child's age as the underlying time scale. The observation time of children who were enumerated at baseline or migrated into the study area is left-truncated. 
Observation ends at death, out-migration, the fifth birthday, or the end of the observation period (30 April 2000).

Observation time of children who migrate between experimental areas is censored at the time of migration and is also censored for a child who migrates from a village where an intervention has already begun to a village in the same area where the intervention has not yet started. The remaining sample used for the analysis represents a total of 53,134 children, 120,238 person-years of observation (a mean of 2.3 years per child), and 5,010 deaths.

All-cause mortality rates are the primary outcome measure, calculated as the number of deaths divided by the total person-time of observation and presented with exact 95 percent confidence intervals (CI). Results are shown for ages 0-59 months and separately for ages $0-11,12-23$, and $24-59$ months. Annual mortality rates are presented for the years 1994-1999 by experimental area. An ordinary least squares regression line was fitted to the series of annual mortality rates in each area and age group to calculate the predicted mean annual change in mortality during the study period.

In each intervention area, mortality rates are compared between person-time accrued prior to the intervention and during the intervention. A child's person-time is classified as pre-intervention up until the date the intervention began in her or his village; these intervention start dates vary from village to village as described above. To illustrate secular trends in mortality during the study period, rates in the comparison area are compared between 1993-95 and 1996-2000. January 1996 was selected as the cutpoint in the comparison area because it corresponds to the median start date of the interventions in villages in the three intervention areas. Results of the analysis do not change if, rather than using January 1996 as the cutpoint for the entire comparison area, villages in the comparison area are randomly assigned "start dates" with the same distribution as the start dates in the intervention areas. Poisson regression models are used to adjust mortality rates for child's sex and birth order; maternal age, education, and residence; and number of household residents.

\section{RESULTS}

The children in the four areas had comparable distributions of most background characteristics (see Table 1). Children in the community-mobilization and combined areas were more likely than those in the other two areas to have mothers and fathers with some formal education, but formal education was uncommon in all four areas. Children in the comparison area tended to live in compounds with fewer members than did those in the other areas. For some children, the biological father and, less frequently, the biological mother were not known.

\section{Time trends in annual child mortality rates}

Figure 2 presents child and infant mortality rates and exact 95 percent confidence intervals for the calendar years 1994-1999 in each intervention area for all person-time and for person-time accrued between 0-11, 12-23, and 24-59 months of age. The boldface

rules superimposed on each set of rates show the predicted mean annual change in child 
mortality rates during the time period. The baseline (1994) under-five mortality rates ranged from 32.3 deaths (per 1,000 person-years of observation) in the communitymobilization area to 49.7 deaths in the $\mathrm{MOH}$-mobilization area. Under-five mortality rates trended upward in the community-mobilization area during the study period, showing an average increase of 1.0 deaths per year, and trended downward in the other three areas, with the $\mathrm{MOH}$ area demonstrating the largest drop ( -4.5 deaths per year), the combined area having the second-largest decline $(-2.5$ deaths per year), and the comparison area the smallest average decline ( -1.1 deaths per year). All areas experienced a spike in mortality in 1996. The etiology of this region-wide increase is unknown (cause-of-death data were not available for this analysis), but the excess of deaths is largely confined to the local rainy season (July to November), suggesting a particularly bad malaria season as a possible explanation. Apart from 1996, mortality fell every year in the MOH area and almost every year in the combined and comparison areas, and increased every year except the last in the community area.

Infant (0-11 months) mortality rates in 1994 ranged from 99.9 deaths per 1,000 person-years of observation in the community-mobilization area to 154.7 deaths in the $\mathrm{MOH}$ area. During the study period, the infant mortality rate fell on average by 8.6 deaths per year in the $\mathrm{MOH}$ area, by 7.0 deaths per year in the combined area, and by 4.4 deaths per year in the comparison area, and remained stable in the community-mobilization area. Comparing the rates for 1999 with those for 1994, mortality declined more in the $\mathrm{MOH}$ mobilization ( -43 percent) and combined ( -26 percent) areas than in the communitymobilization ( -8 percent) and comparison ( -9 percent) areas.

Early childhood (12-23 months) mortality rates in 1994 ranged from 20.2 deaths per 1,000 person-years of observation in the community-mobilization area to 46.3 deaths in the comparison area. The mortality rate increased on average by 4.5 deaths per year in the community-mobilization area and decreased on average by 5.0 deaths per year in the $\mathrm{MOH}$ area, by 2.9 deaths per year in the combined area, and by 0.8 deaths per year in the comparison area.

Late childhood (24-59 months) mortality rates in 1994 ranged from 13.2 deaths in the community-mobilization area to 16.6 deaths in the comparison area. The mortality rate declined on average by 2.0 deaths per year in the $\mathrm{MOH}$ area during the study period for an overall decline of 65 percent between 1994 and 1999. The mortality rate decreased more modestly in the combined area (by -0.8 deaths on average per year) and remained approximately stable in the community-mobilization ( 0.0 deaths per year) and comparison $(+0.1$ deaths per year) areas. By 1999 , the rate in the $\mathrm{MOH}$ area was approximately half as high as in the other three areas.

CHFP interventions were being scaled up between 1994 and 1996, so that some villages had programs in place in these years while others did not. In the community area, mortality rates were higher among unexposed children compared to the exposed in 1995, but the reverse was true in 1996 (see Table 2). In 1997 and 1998, when the intervention had reached all villages, mortality was higher than it had been in 1994 or 1995 . Mortality fell in 1999 but remained about 10 percent above the 1994 level. 
In the $\mathrm{MOH}$ area, mortality was comparable between exposed and unexposed children in 1994 and 1995, but higher among exposed children in 1996. Mortality fell each year from 1997 to 1999, ending at about half the 1994 level. In the combined area, mortality was higher among exposed compared with unexposed children in 1994, 1995, and 1996. Mortality fell each year from 1997 to 1999, ending about 25 percent below the 1994 level. In the comparison area, mortality varied but generally trended slightly downward over time, ending in 1999 at about 15 percent below the 1994 level.

\section{Preintervention versus intervention mortality}

Table 3 compares mortality rates between person-time prior to and during the intervention in the three intervention areas. In the comparison area, person-time in 199395 is compared with person-time in 1996-2000 in order to illustrate the regional changes in mortality that occurred during the study period independent of the CHFP. The adjusted under-five mortality rate was 11 percent higher in the community-mobilization area during the intervention compared with the rate prior to the intervention $(\mathrm{RR}=1.11)$. This increase was driven primarily by a large increase in the early childhood mortality rate $(\mathrm{RR}=1.87)$. In the $\mathrm{MOH}$ area, the under-five mortality rate decreased by 14 percent during the intervention $(\mathrm{RR}=0.86)$; mortality fell in all age groups, with the largest drop occurring during late childhood $(\mathrm{RR}=0.64)$. In the combined area, the under-five mortality rate increased by 8 percent $(R R=1.08)$, with small increases in all age groups. In the comparison area, mortality dropped by 6 percent $(R R=0.94)$ due to the offsetting effects of a modest decrease in the infant mortality rate $(\mathrm{RR}=0.88)$ and a modest increase in the late childhood mortality rate $(\mathrm{RR}=1.10)$.

These results remain substantively unchanged when the mortality rates are adjusted (using Poisson regression) for child's sex and birth order; mother's age, education, and residence; and number of household residents (see Table 4).

\section{DISCUSSION}

The Navrongo Community Health and Family Planning Project represents a trial of the impact of mobilizing two sets of underused resources that are generally available at low cost for health care throughout sub-Saharan Africa. The community-mobilization arm tests the marshalling of social resources that govern village life and are available to health-care systems but that typically are ignored by health planners and administrators. The $\mathrm{MOH}-$ mobilization arm tests the effectiveness of moving health-care resources out of underused subdistrict clinics and into communities, where accountability for health-care service delivery can be assured and accessibility can be achieved. The combined arm tests the synergy between these two strategies.

We found that under-five mortality was fairly stable in the comparison area before and during CHFP implementation, whereas in the $\mathrm{MOH}-$ mobilization arm, child mortality fell during the intervention compared with the period before its implementation. The largest decrease occurred for those in late childhood. Mortality increased to some degree in the community-mobilization arm, particularly in early childhood where mortality nearly doubled during the intervention. In the combined arm, mortality was higher among 
children exposed to the intervention compared with those who were unexposed while the project was being scaled up, but fell over time once the intervention was fully in place.

Many mechanisms may explain how the location in villages of trained nurses with doorstep service-delivery responsibilities may have reduced child mortality, including improved vaccination coverage, more rapid diagnosis and treatment of illnesses, and health education. The substantial decline in mortality among older children, many of whom were exposed to the intervention for several years, may reflect the cumulative gains in resilience and survival for children who are consistently treated for acute respiratory infections, diarrhea, malaria, and other illnesses. It may also reflect improved coverage with measles vaccination, which is administered in infancy but has been demonstrated to reduce sharply all-cause mortality in later years both in this population and in other populations facing multiple health challenges (Koenig et al. 1991; Aaby 1995; Kristensen et al. 2000; Nyarko et al. 2001). Data concerning immunization coverage prior to the intervention are not available. During the program period, coverage with all immunizations has been markedly higher in the three intervention areas relative to the comparison area but has not differed greatly among the three intervention areas (Nyarko et al. 2003). For example, the proportion of 12-month-olds vaccinated against measles between 1996 and 1999 was 52 percent in the community-mobilization area, 48 percent in the MOH-mobilization area, 49 percent in the combined area, and 37 percent in the comparison area.

The finding that mortality, especially early childhood mortality, rose in the community-mobilization area during the CHFP was surprising and has sparked speculation that the presence of health volunteers, particularly in the absence of nurses in the village, may make residents less likely to seek health care from the more skilled medical providers in the subdistrict clinics. In the second year of life, acute respiratory infections and diarrheal disease are two of the leading causes of death in the area. Mothers may first seek advice and basic treatment from volunteers in situations where they would otherwise have taken their children to the clinic, thereby delaying or preventing the delivery of appropriate treatment. The contribution of volunteers, who as part of the CHFP are provided with certain basic medications such as paracetamol, may be more beneficial if their activities are limited to health education, outreach coordination, and family planning provision, for which they have been shown to be effective service providers (Phillips et al. 2000a; Debpuur et al. 2002).

The results for the combined arm of the study, where mortality was higher among children exposed to the intervention compared with those who were unexposed during the early stages of the project but fell once the intervention was in place, may indicate that the most disadvantaged villages were the first ones chosen to receive the intervention. The results also could reflect startup difficulties in the coordination of nurse and volunteer activities. Mortality eventually declined, but the decrease was smaller than that observed in the $\mathrm{MOH}$ arm. This finding may represent contrary effects of the nurse and the volunteer: the presence of a volunteer may divert health-seeking behavior even when the nurse lives in the village and visits households on a regular basis. Residents may receive conflicting messages or signals from the volunteer and the nurse about the appropriate first place to 
turn for medical care, preventing nurses from achieving the same reductions in mortality as are seen in the $\mathrm{MOH}$ area.

Project staff undertook a cross-sectional investigation of child morbidity and of health-seeking behavior in the study area after the mortality findings in this report were circulated in preliminary form to investigate whether volunteers were diverting healthseeking behavior (Nyarko et al. 2003). The study found comparable levels of child morbidity in the four areas, but persistent diarrhea (the second-leading cause of death in the district) was more common in the community and comparison areas, suggesting that clients experienced a longer delay in receiving treatment for diarrhea in the areas lacking community health nurses. Parents of sick children were more likely to consult professional health staff in the $\mathrm{MOH}$ and combined areas; parents in the community and comparison areas more commonly first consulted a traditional healer or soothsayer than did parents in the areas with nurses. Parents in the community and comparison areas rarely turned first to a health volunteer for help with a sick child. This cross-sectional survey took place almost a year after the mortality findings had been circulated, and, in the interim, project staff had emphasized to volunteers that they should be referring rather than treating illnesses.

The large population under study $(140,000)$, the rigorous demographic surveillance system with detailed information on person-time at risk and comprehensive capture of mortality events, the availability of mortality information both before and during program implementation in each area, and the inclusion of a comparison area are key strengths of this study. A primary limitation is the presence of only one area per treatment condition. Because the CHFP interventions were not randomized at the level of the individual, traditional variance estimators based on the assumption of independence between observations will underestimate the true variance in parameter estimates and produce overly narrow confidence intervals (Simpson et al. 1995). Variance estimators cannot be corrected for this lack of independence because each treatment condition was assigned to only one area (Murray 1998). Parameter estimates themselves, however, will be unbiased. This problem is difficult to avoid in community-based interventions that for reasons of administration and contamination often cannot be randomized realistically at a level below the community or even the group of communities. Therefore, tests of statistical significance and examination of confidence intervals should not be relied upon for interpreting the results of the CHFP.

Although it is far from definitive, the report from this large, controlled community health trial in an impoverished area of rural sub-Saharan Africa should stimulate discussion and further research on the implications of mobilizing health volunteers in such settings. For decades, proposals such as the Bamako Initiative have promoted the mobilization of traditional community structures for the delivery of health care in less-developed countries with little hard evidence to support their recommendations. At the least, these results should influence the design of further community-level trials to evaluate the effect of community volunteers on health-seeking behavior, child morbidity, and survival in different settings. 
Several other programs have succeeded in reducing child mortality with similar community-based primary-health-care interventions. In Bolivia, mortality rates were 52 percent lower in areas receiving primary-health-care program activities involving both community-based nurses and volunteers than mortality rates observed in nonprogram areas (Perry et al. 2003). A similar program in the Gambia reduced child mortality by 33 percent in program areas compared with 16 percent in nonprogram areas (Hill et al. 1998 and 2000). These programs did not examine the effects of nurses and volunteers independently. In Matlab, Bangladesh, reductions in neonatal (17 percent), infant ( 9 percent), and child (30 percent) mortality were achieved by a program that relied primarily on community health workers whose responsibilities were similar to those of the volunteers in the present study and who were supervised by centrally located medical personnel (Fauveau 1990). Differences in the training of volunteers, in the specific responsibilities they were assigned, in their coordination with medical personnel, or in local traditional health-care practices may underlie the differences in the Matlab and Navrongo experiences. Examples of null or deleterious program effects are hard to find in the literature, possibly because negative results are less likely to be published.

In our analysis, we were unable to control for the extent to which program implementation or effectiveness may have varied within treatment arms, that is, across nurses or volunteers in different villages in the same area. The reported results, therefore, represent an effectiveness trial rather than an efficacy trial. The observed changes in mortality are what one might expect to see in real-world implementation with variation in service quality, rather than in ideal and rigorously managed circumstances.

The results of the Navrongo Community Health and Family Planning Project provide evidence that relocating trained nurses to village residences where they are easily accessible to the community may reduce child mortality. The MOH-mobilization strategy likely operates through improved treatment of acute respiratory infections, malaria, and diarrhea, and possibly through improved childhood vaccination coverage. In contrast, the Navrongo experience with community health volunteers raises questions about the efficacy of this approach in reducing child mortality. Indeed, the CHFP provides evidence that this popular model may increase child mortality in some contexts, possibly by diverting mothers' health-seeking behavior from trained paramedical care to the more accessible and less expensive but also less thoroughly trained volunteers. Thus, the CHFP underscores the scientific and policy value of field trials, even for intuitively appealing health-service interventions. Further research on the effects of village-based nurses and volunteers on children's health outcomes should be conducted in other field stations in less-developed countries to assess the wider applicability of these findings. 


\section{REFERENCES}

Aaby, P. 1995. "Assumptions and contradictions in measles and measles immunization research: Is measles good for something?" Social Science \& Medicine 41(5): 673-686.

Amonoo-Lartson, R. 1981. "Change in family health care policy: The Ghanaian experience." In The Non-physician and Family Health in Sub-Saharan Africa: Proceedings of a Conference. Eds. R.S. Waife and M.C. Burkhart. Chestnut Hill, MA: Pathfinder Fund. Pp. 108-115.

Berman, P.A., D.R. Gwatkin, and S.E. Burger. 1987. "Community-based health workers: Head start or false start toward health for all?" Social Science \& Medicine 25(5): 443459.

Binka, F.N., S.S. Morris, D.A. Ross, P. Arthur, and M.E. Aryeetey. 1994. "Patterns of malaria morbidity and mortality in children in northern Ghana." Transactions of the Royal Society of Tropical Medicine and Hygiene 88(4): 381-385.

Binka, F.N., G.H. Maude, M. Gyapong, D.A. Ross, and P.G. Smith. 1995a. "Risk factors for child mortality in northern Ghana: A case control study." International Journal of Epidemiology 24(1): 127-135.

Binka, F.N., A. Nazzar, and J.F. Phillips. 1995b. "The Navrongo Community Health and Family Planning Project.” Studies in Family Planning 26(3): 121-139.

Binka, F.N., D.A. Ross, S. Morris, B. Kirkwood, P. Arthur, N. Dollimore, J.O. Gyapong, and P.G. Smith. 1995c. "Vitamin A supplementation and childhood malaria in northern Ghana." American Society for Clinical Nutrition 61(4): 853-859.

Binka, F.N., O.A. Mensah, and A. Mills. 1997a. "The cost-effectiveness of permethrinimpregnated bednets in preventing child mortality in Kassena-Nankana District of Northern Ghana." Health Policy 41(3): 229-239.

Binka, F.N., P. Ngom, J.F. Phillips, K. Adazu, and B.B. MacLeod. 1997b. “Assessing population dynamics in a rural African society: The Navrongo Demographic Surveillance System.” Paper presented at the International Union for the Scientific Study of Population General Population Conference, Beijing, 11-17 October.

Debpuur, C., J.F. Phillips, E.F. Jackson, A.K. Nazzar, P. Ngom, and F.N. Binka. 2002. “The impact of the Navrongo Project on contraceptive knowledge and use, reproductive preferences, and fertility." Studies in Family Planning 33(2): 141-164. 
Dollimore, N., F. Cutts, F.N. Binka, D.A. Ross, S.S. Morris, and P.G. Smith. 1997. "Measles incidence, case fatality, and delayed mortality in children with or without Vitamin A supplementation in rural Ghana." American Journal of Epidemiology 146(8): 646-654.

Fauveau, V., B. Wojtyniak, J. Chakraborty, A.M. Sarder, and A. Brierd. 1990. "The effect of maternal and child health and family planning services on mortality: Is prevention enough?” British Medical Journal 301(6,743): 103-107.

Ghana Health Service (GHS). 2004. HIV Sentinel Survey, 2003 Report. Accra, Ghana: National AIDS/STI Control Program.

Ghana Statistical Service (GSS), Noguchi Memorial Institute for Medical Research (NMIMR), and ORC Macro. 2004. Ghana Demographic and Health Survey 2003. Calverton, MD: GSS, NMIMR, and ORC Macro.

Gwatkin, D.R. 1980. "Indications of change in developing country mortality trends: The end of an era?" Population and Development Review 6(4): 615-644.

Gwatkin, D.R., A. Bhuiya, and C.G. Victora. 2004. "Making health systems more equitable." The Lancet 364(9,441): 1,273-1,280.

Hill, K. and A.R. Pebley. 1989. "Child mortality in the developing world." Population and Development Review 15(4): 657-687.

Hill, A.G., W.B. MacLeod, S.S. Sonko, and G. Walraven. 1998. "Improvements in child mortality in the Gambia." The Lancet 352(9,144): 1,909.

Hill, A.G., W.B. MacLeod, D. Joof, P. Gomez, and G. Walraven. 2000. "Decline of mortality in children in rural Gambia: The influence of village-level primary care." Tropical Medicine and International Health 5(2): 107-118.

Knippenberg, R., D, Levy-Bruhl, R. Osseni, K. Drame, A. Soucat, and C. Debeugny. 1990. The Bamako Initiative: Primary Health Care. New York: UNICEF.

Koenig, M.A., M.A. Khan, B. Wojtyniak, J.D. Clemens, J. Chakraborty, V. Fauveau, J.F. Phillips, J. Akbar, and U.S. Barua. 1991. "Impact of measles vaccination on childhood mortality in rural Bangladesh." Bulletin of the World Health Organization 68(4): 441447.

Kristensen, I., P. Aaby, and H. Jensen. 2000. "Routine vaccinations and child survival: Follow-up study in Guinea-Bissau, West Africa." British Medical Journal 321(7,274): $1,435-1,438$. 
Mosley, W. Henry. 1984. "Child survival: Research and policy." Population and Development Review 10(supplement): 3-23.

- 1985. "Will primary health care reduce infant and child mortality?" In Health Policy, Social Policy and Mortality Prospects. Eds. J. Vallin and A.D. Lopez. Liège: Ordina Editions. Pp. 103-137.

Murray, D.M. 1998. Design and Analysis of Group-Randomized Trials. New York: Oxford University Press.

Navrongo Health Research Centre (NHRC). 1998. The Navrongo Community Health and Family Planning Project: Lessons Learned, 1994-1998. Navrongo, Ghana: NHRC.

Ngom, P., F.N. Binka, J.F. Phillips, B. Pence, and B. MacLeod. 2001. "Demographic surveillance and health equity in sub-Saharan Africa: Past and present efforts." Health Policy and Planning 16(4): 337-344.

Nyarko, P.E., R. Asuru, B. Pence, P. Akweongo, P. Adongo, J. Ablordeppey, and A. Hodgson. 2003. Child Mortality and Health-Seeking Behavior of Primary Caretakers in the Kassena-Nankana District. Navrongo, Ghana: Navrongo Health Research Centre.

Nyarko, P., B. Pence, and C. Debpuur. 2001. "Immunization Status and Child Survival in Rural Ghana." Policy Research Division Working Paper No. 147. New York: Population Council.

Perry, H.B., D.S. Shanklin, and D.G. Schroeder. 2003. "Impact of a community-based comprehensive primary healthcare program on infant and child mortality in Bolivia." Journal of Health, Population and Nutrition 21(4): 383-395.

Phillips, J.F., C. Debpuur, A. Nazzar, and E.F. Jackson. 2000a. "The impact of the Navrongo Community Health and Family Planning Project on fertility." Paper presented at the Population Association of America Annual Meetings, Los Angeles, 23-25 March.

Phillips, J.F., B.B. MacLeod, and B. Pence. 2000b. "The Household Registration System: Computer software for the rapid dissemination of demographic surveillance systems." Demographic Research 2: article 6. <http://www.demographicresearch.org/Volumes/Vol2/6/default.htm>. Accessed 22 June 2005.

Shier, R.P., N. Dollimore, D.A. Ross, F.N. Binka, M. Quigley, and P.G. Smith. 1996. "Drinking water sources, mortality and diarrhoea morbidity among young children in northern Ghana." Tropical Medicine and International Health 1(3): 334-341. 
Simpson, J.M., N. Klar, and A. Donner. 1995. "Accounting for cluster randomization: A review of primary prevention trials, 1990 through 1993." American Journal of Public Health 85(10): 1,378-1,383.

UNAIDS. 2004. 2004 Report on the Global AIDS Epidemic: $4^{\text {th }}$ Global Report. Geneva: Joint United Nations Program on AIDS (UNAIDS).

UNICEF. 1986. The State of the World's Children 1985. Oxford: Oxford University Press.

—. 2004. The State of the World's Children 2005. New York: UNICEF.

World Bank. 1994. Better Health in Africa: Experiences and Lessons Learned. Washington, DC: The World Bank.

World Health Organization (WHO). 1978. Report of the Alma-Ata Conference on Primary Health Care. Health for All Series No. 1. Geneva: WHO. 
Figure 1 Community Health and Family Planning Project study design, Navrongo, Ghana

Mobilize Ministry of

Health $(\mathrm{MOH})$ outreach?

Yes

No
Mobilize traditional community resources?

No

Area 2

MOH mobilization only

Area 1

Community mobilization only
Area 4

Comparison:

Standard MOH Services 
Table 1 Means (standard deviations) and percentages of sample by background characteristics, according to type of intervention area, Navrongo, Ghana, 1993-2000

\begin{tabular}{|c|c|c|c|c|c|}
\hline \multirow[b]{2}{*}{ Characteristic } & \multicolumn{4}{|c|}{ Intervention area } & \multirow[b]{2}{*}{$\mathrm{N}$} \\
\hline & Community & MOH & Combined & Comparison & \\
\hline \multicolumn{6}{|l|}{ Child } \\
\hline Number in analysis & 8,218 & 8,109 & 18,350 & 18,457 & 53,134 \\
\hline Percent who died while under observation & 8.8 & 10.1 & 8.9 & 9.9 & 53,134 \\
\hline Mean years under observation (SD) & $2.3(1.6)$ & $2.2(1.6)$ & $2.3(1.6)$ & $2.2(1.6)$ & 53,134 \\
\hline Percent female & 49.0 & 50.6 & 50.2 & 50.1 & 53,133 \\
\hline Birth order: 1 & 27.6 & 26.2 & 27.1 & 24.9 & 51,240 \\
\hline 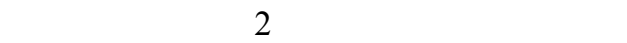 & 21.3 & 23.0 & 22.2 & 21.0 & \\
\hline 3 & 17.8 & 20.1 & 19.4 & 18.7 & \\
\hline $4+$ & 33.3 & 30.7 & 31.2 & 35.4 & \\
\hline \multicolumn{6}{|l|}{ Mother } \\
\hline Mean age in years (SD) & $28.2(7.7)$ & $28.2(7.2)$ & $28.1(7.2)$ & $28.7(7.4)$ & 51,040 \\
\hline Percent with any formal education & 16.7 & 10.8 & 17.1 & 6.4 & 51,040 \\
\hline Percent resident in household with child & & & & & 49,683 \\
\hline Never & 2.4 & 1.9 & 2.4 & 1.8 & \\
\hline Sometimes & 8.2 & 7.7 & 8.7 & 6.1 & \\
\hline Always & 89.4 & 90.4 & 88.9 & 92.1 & \\
\hline \multicolumn{6}{|l|}{ Father } \\
\hline Mean age in years $(\mathrm{SD})$ & $38.3(11.9)$ & $38.6(12.7)$ & $37.4(11.1)$ & $39.0(12.0)$ & 43,674 \\
\hline Percent with any formal education & 20.2 & 15.8 & 20.8 & 11.4 & 43,674 \\
\hline Percent resident in household with child & & & & & 40,502 \\
\hline Never & 2.8 & 2.6 & 2.7 & 2.1 & \\
\hline Sometimes & 6.3 & 6.7 & 6.6 & 5.3 & \\
\hline Always & 90.8 & 90.7 & 90.7 & 92.6 & \\
\hline $\begin{array}{l}\text { Number of residents in household } \\
\text { (percent) }\end{array}$ & & & & & 53,120 \\
\hline $2-10$ & 23.2 & 25.6 & 27.4 & 38.2 & \\
\hline $11-20$ & 34.6 & 36.9 & 37.7 & 40.5 & \\
\hline $21+$ & 42.2 & 37.5 & 34.8 & 21.3 & \\
\hline
\end{tabular}


Figure 2 Annual child and infant mortality rates (deaths per 1,000 person-years observed), by age group and intervention area, Navrongo, Ghana, 1994-99

Ages 0-59 months

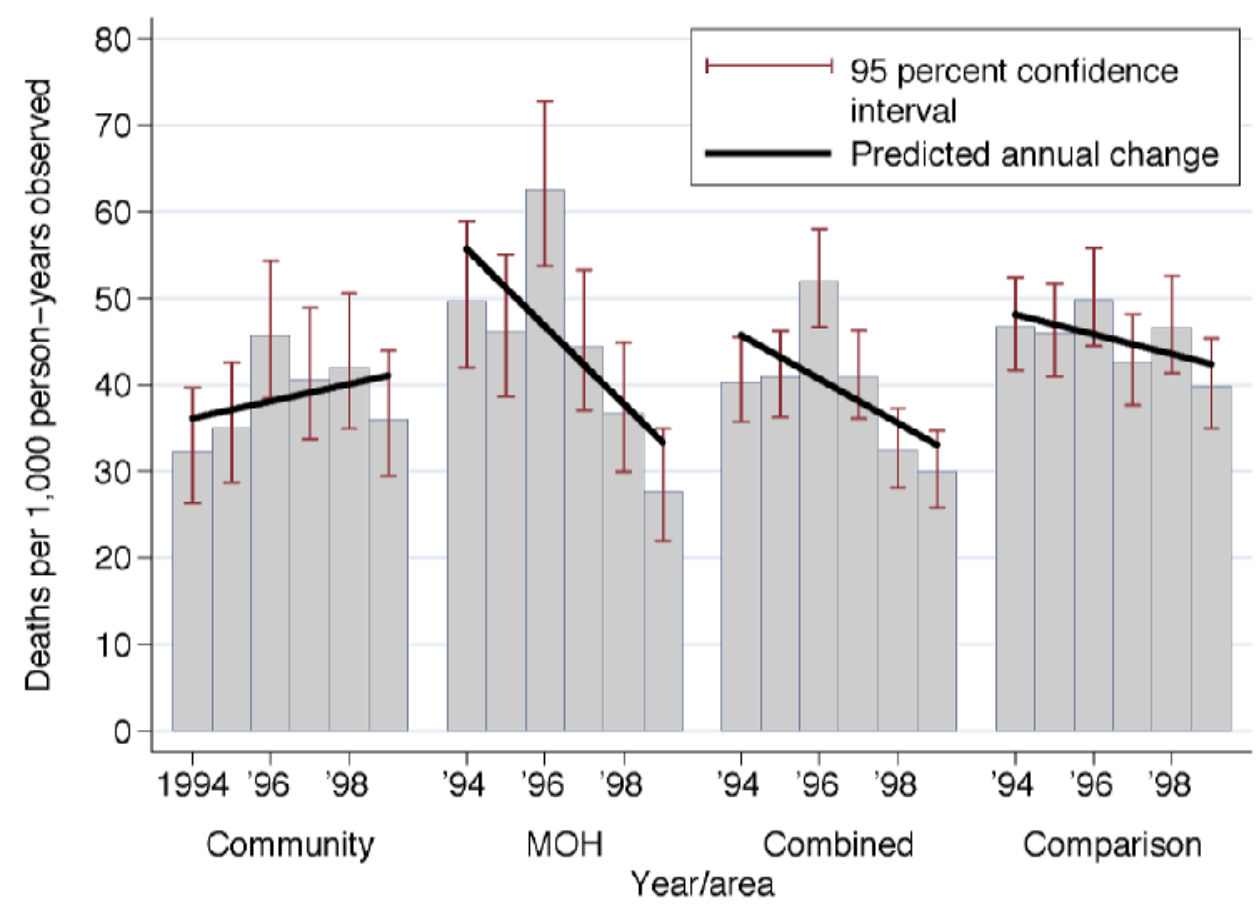

Ages 0-11 months

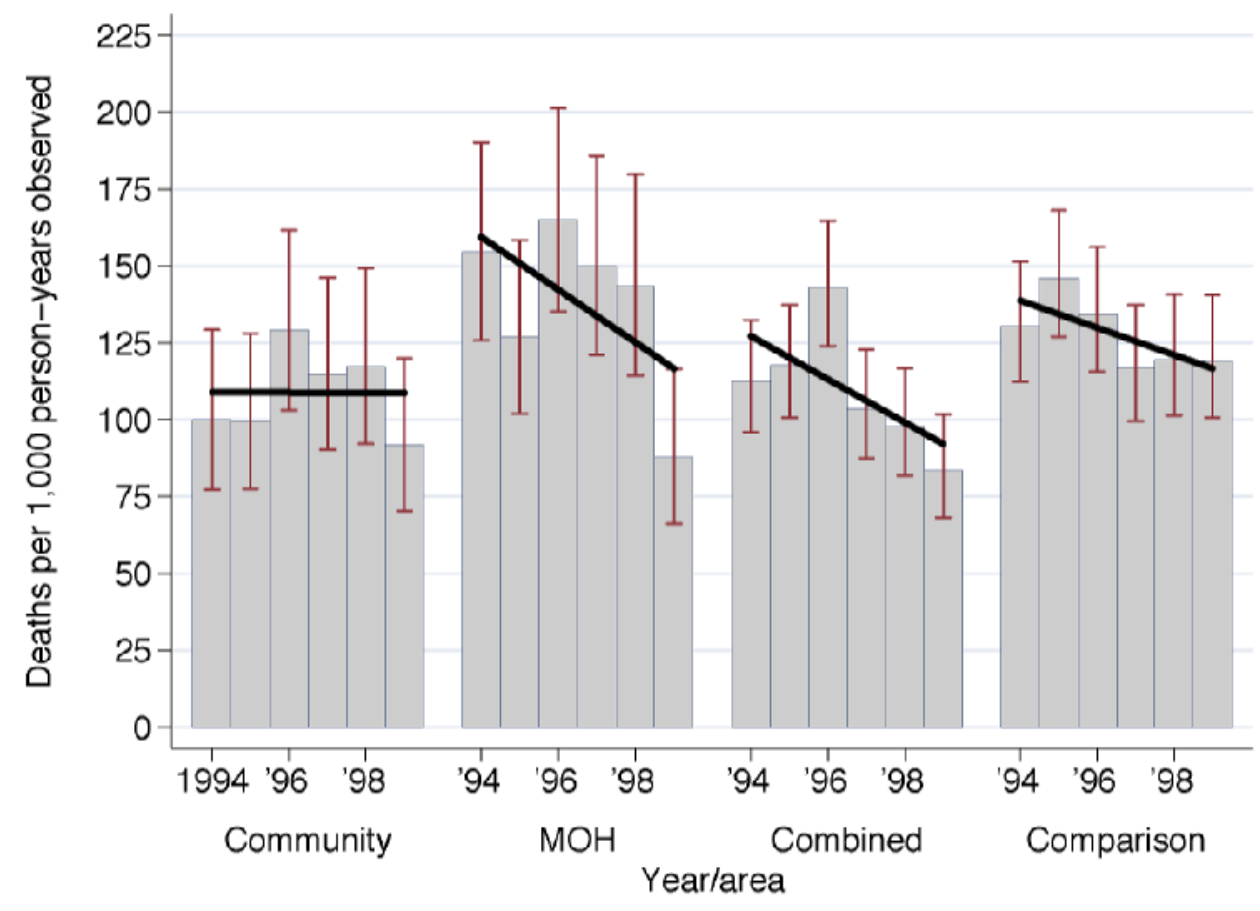


Figure 2 (continued)

Ages 12-23 months

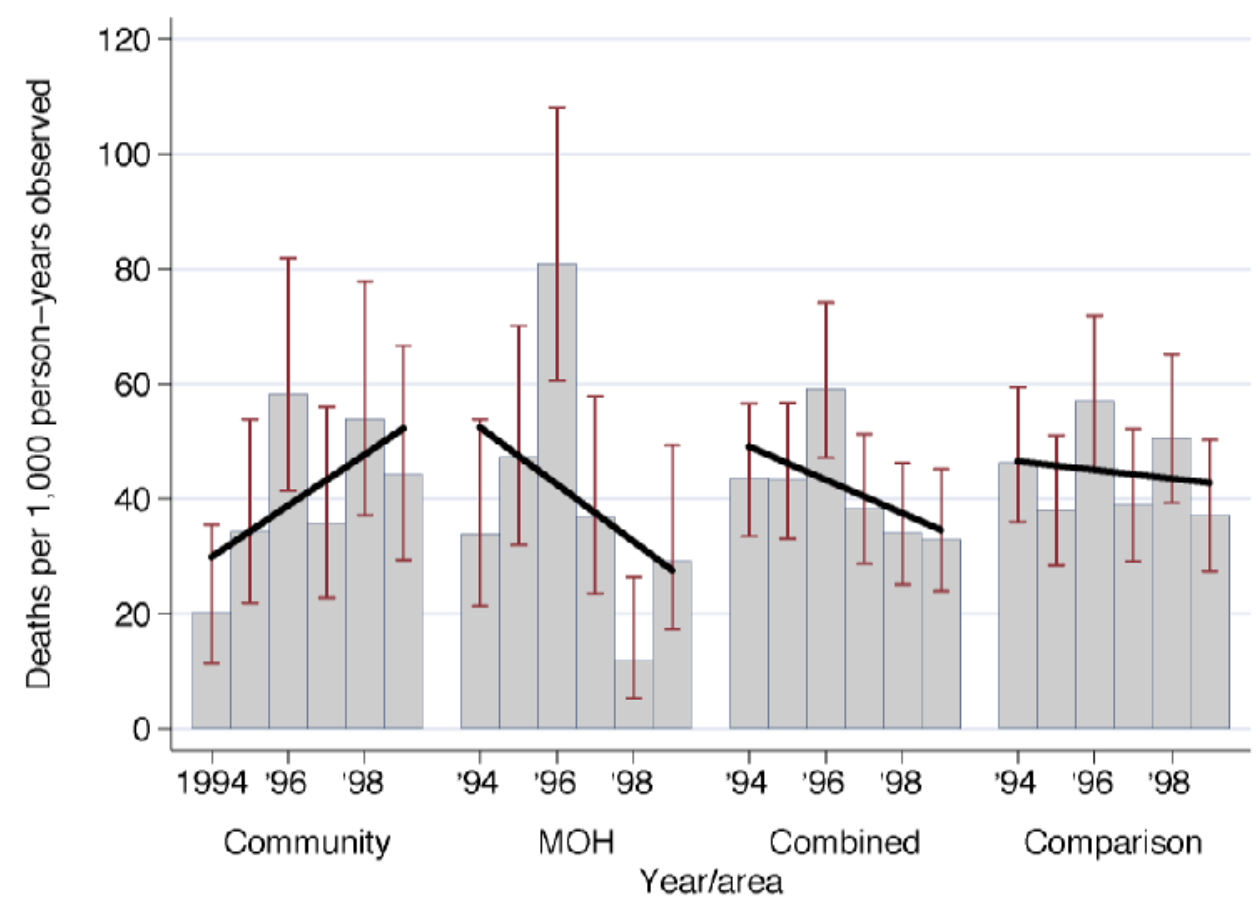

Ages 24-59 months

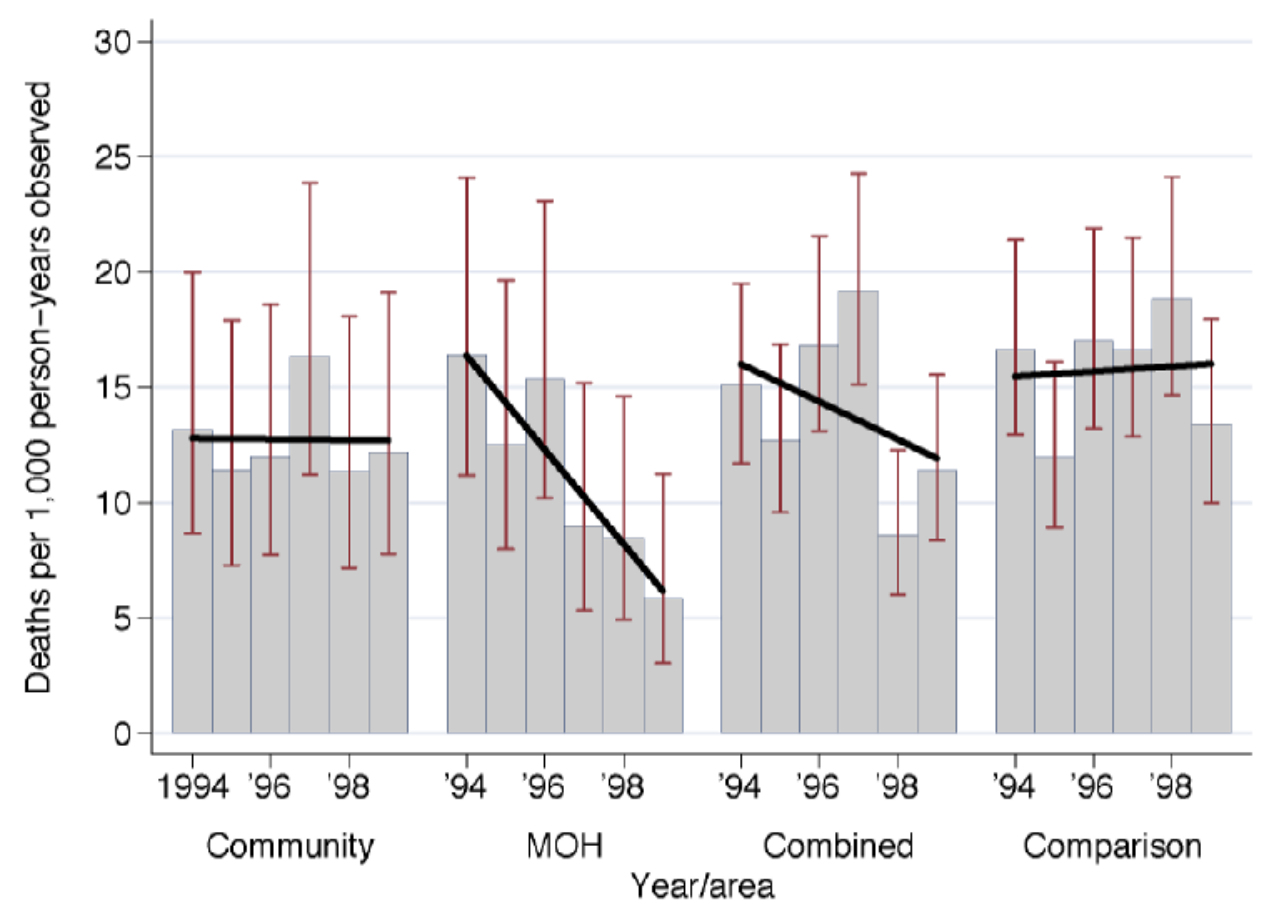


Table 2 Mortality rates (deaths per 1,000 PYO) for children aged 0-59 months by intervention area, year, and exposure to CHFP interventions, 1994-99

\begin{tabular}{|c|c|c|c|c|c|c|c|}
\hline \multirow[b]{2}{*}{ Area } & \multirow[b]{2}{*}{ Exposure Status } & \multicolumn{6}{|c|}{ Year } \\
\hline & & 1994 & 1995 & 1996 & 1997 & 1998 & 1999 \\
\hline \multirow{3}{*}{ Community } & Unexposed & 32.3 & 38.9 & 26.7 & - & - & - \\
\hline & Exposed & 一 & 26.9 & 48.3 & 40.6 & 42.0 & 36.0 \\
\hline & $\begin{array}{l}\text { Percent of PYO } \\
\text { exposed }\end{array}$ & 0.0 & 33.0 & 88.0 & 100.0 & 100.0 & 100.0 \\
\hline \multirow[t]{3}{*}{$\mathrm{MOH}$} & Unexposed & 50.0 & 47.0 & 45.6 & - & - & - \\
\hline & Exposed & 48.0 & 44.8 & 67.6 & 44.4 & 36.7 & 27.7 \\
\hline & $\begin{array}{l}\text { Percent of PYO } \\
\text { exposed }\end{array}$ & 18.0 & 39.0 & 77.0 & 100.0 & 100.0 & 100.0 \\
\hline \multirow[t]{3}{*}{ Combined } & Unexposed & 37.8 & 36.1 & 43.6 & - & - & - \\
\hline & Exposed & 54.9 & 57.6 & 55.0 & 40.9 & 32.4 & 29.9 \\
\hline & $\begin{array}{l}\text { Percent of PYO } \\
\text { exposed }\end{array}$ & 15.0 & 22.0 & 74.0 & 100.0 & 100.0 & 100.0 \\
\hline Comparison & - & 46.8 & 46.0 & 49.8 & 42.6 & 46.6 & 39.8 \\
\hline
\end{tabular}

$\mathrm{PYO}=$ Person-years of observation. CHFP $=$ Navrongo Community Health and Family Planning Project. $-=$ Not applicable. 
Table 3 Mortality rates per 1,000 PYO (deaths/PYO) for children exposed and not exposed to CHFP interventions and rate ratios (95 percent confidence intervals), by age group and area, Navrongo, Ghana, 1993-2000

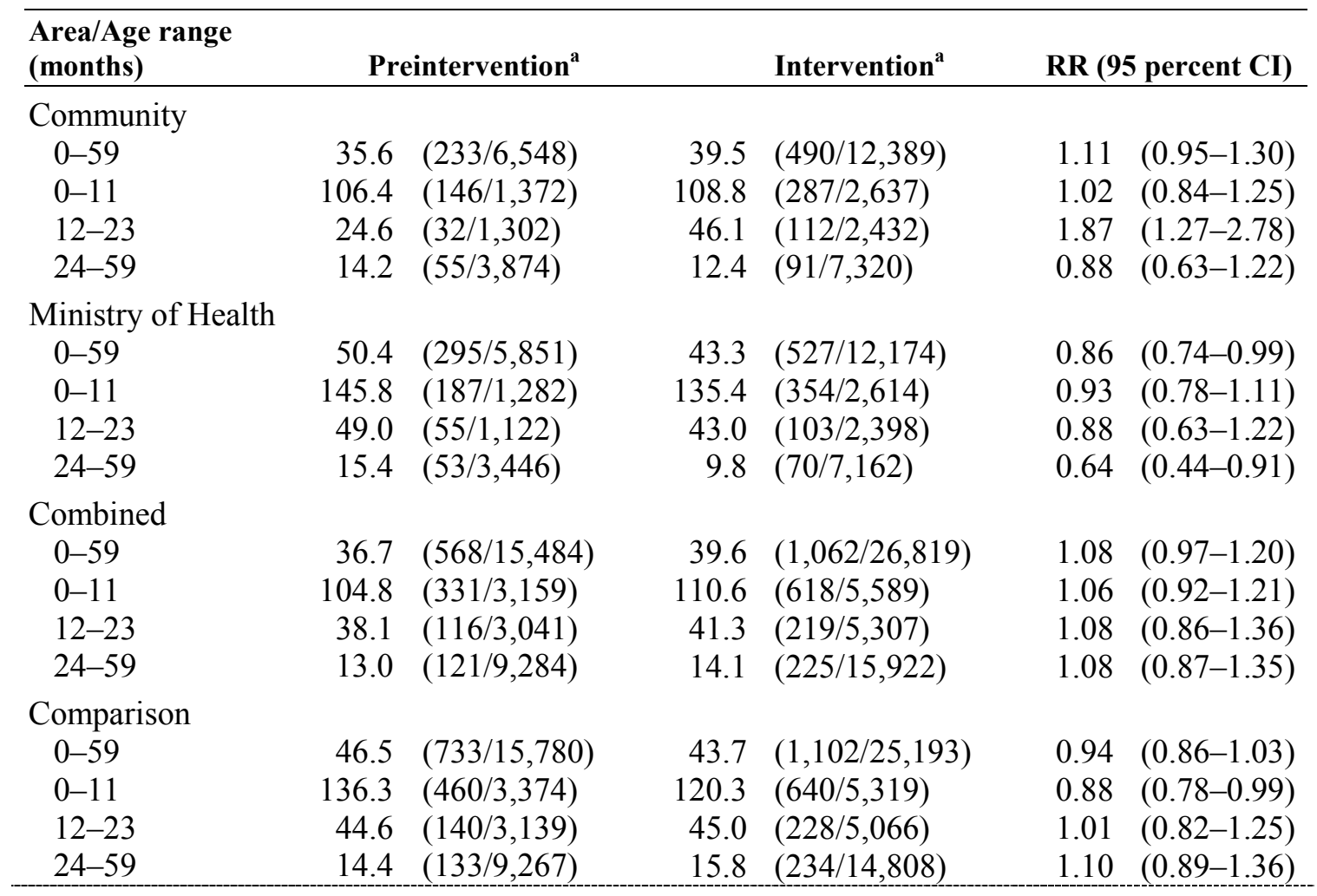

$\mathrm{PYO}=$ Person-years of observation. $\mathrm{CHFP}=$ Navrongo Community Health and Family Planning Project. $\quad \mathrm{RR}=$ Rate ratio. $\quad \mathrm{CI}=$ Confidence interval.

"In the comparison area, 1993-95 is treated as "preintervention" and 1996-2000 is treated as "intervention" time. 
Table 4 Rate ratios (95 percent confidence intervals) from Poisson regression models comparing child mortality before and during CHFP interventions and controlling for background characteristics, by age group, Navrongo, Ghana, 1993-2000

\begin{tabular}{|c|c|c|c|c|}
\hline \multirow[b]{2}{*}{ Variable } & \multicolumn{4}{|c|}{ Age range } \\
\hline & 0-59 months & 0-11 months & 12-23 months & 24-59 months \\
\hline \multicolumn{5}{|l|}{ Intervention versus preintervention $^{\mathrm{a}}$} \\
\hline Community & $1.11(0.95-1.31)$ & $1.00(0.81-1.22)$ & $2.24(1.46-3.44)$ & $0.86(0.60-1.23)$ \\
\hline Ministry of Health & $0.84(0.73-0.98)$ & $0.94(0.78-1.13)$ & $0.80(0.56-1.14)$ & $0.59(0.41-0.86)$ \\
\hline Combined & $1.07(0.96-1.19)$ & $1.05(0.91-1.20)$ & $1.09(0.86-1.38)$ & $1.06(0.84-1.35)$ \\
\hline Comparison & $0.95(0.86-1.04)$ & $0.89(0.79-1.01)$ & $1.05(0.84-1.31)$ & $1.07(0.85-1.34)$ \\
\hline \multicolumn{5}{|l|}{ Baseline differences between cells } \\
\hline Community & $0.77(0.66-0.90)$ & $0.83(0.69-1.01)$ & $0.50(0.32-0.76)$ & $0.95(0.68-1.32)$ \\
\hline Ministry of Health & $1.12(0.97-1.29)$ & $1.11(0.93-1.32)$ & $1.09(0.78-1.52)$ & $1.12(0.80-1.56)$ \\
\hline Combined & $0.81(0.72-0.91)$ & $0.80(0.69-0.93)$ & $0.89(0.69-1.15)$ & $0.90(0.69-1.16)$ \\
\hline Comparison & $1.00-$ & $1.00-$ & $1.00-$ & $1.00-$ \\
\hline \multicolumn{5}{|l|}{ Background characteristic } \\
\hline Male child & $1.04(0.98-1.10)$ & $1.02(0.95-1.10)$ & $1.13(0.99-1.28)$ & $1.10(0.96-1.26)$ \\
\hline \multicolumn{5}{|l|}{ Birth order } \\
\hline Oldest & $1.00-$ & $1.00-$ & $1.00-$ & $1.00-$ \\
\hline Second & $0.84(0.76-0.93)$ & $0.77(0.68-0.88)$ & $1.06(0.85-1.33)$ & $0.86(0.68-1.08)$ \\
\hline Third & $0.90(0.81-1.00)$ & $0.80(0.70-0.92)$ & $1.04(0.82-1.32)$ & $1.02(0.81-1.28)$ \\
\hline Fourth or younger & $0.95(0.85-1.06)$ & $0.76(0.66-0.87)$ & $1.12(0.88-1.43)$ & $0.99(0.78-1.26)$ \\
\hline \multicolumn{5}{|l|}{ Mother's age at birth of child } \\
\hline$<20$ & $1.00-$ & $1.00-$ & $1.00-$ & $1.00-$ \\
\hline $20-29$ & $0.73(0.66-0.82)$ & $0.79(0.69-0.91)$ & $0.94(0.72-1.22)$ & $0.95(0.72-1.26)$ \\
\hline $30-39$ & $0.80(0.70-0.91)$ & $0.96(0.82-1.13)$ & $0.91(0.67-1.24)$ & $0.96(0.70-1.33)$ \\
\hline $40+$ & $1.00(0.86-1.16)$ & $1.25(1.03-1.51)$ & $1.12(0.78-1.60)$ & $1.03(0.71-1.50)$ \\
\hline Mother has had any formal education & $0.84(0.76-0.92)$ & $0.81(0.72-0.92)$ & $0.68(0.53-0.86)$ & $0.80(0.63-1.01)$ \\
\hline Mother is resident in compound & $0.90(0.77-1.06)$ & $0.96(0.77-1.19)$ & $0.77(0.53-1.12)$ & $0.69(0.50-0.97)$ \\
\hline \multicolumn{5}{|l|}{ Number of residents in compound } \\
\hline$<11$ & $1.00-$ & $1.00-$ & $1.00-$ & $1.00-$ \\
\hline $11-20$ & $1.07(1.00-1.15)$ & $1.03(0.95-1.13)$ & $1.15(0.98-1.35)$ & $1.07(0.91-1.27)$ \\
\hline $21+$ & $1.01(0.94-1.09)$ & $0.90(0.82-0.99)$ & $1.19(1.01-1.41)$ & $1.19(1.00-1.41)$ \\
\hline Deaths & 4,623 & 2,853 & 912 & 858 \\
\hline Person-years of observation & 110,432 & 23,986 & 22,442 & 64,004 \\
\hline-2 log likelihood ratio $\mathrm{Chi}^{2}$ (degrees & & & & \\
\hline of freedom) & $159.93(18)$ & $132.23(18)$ & $47.20(18)$ & $32.31(18)$ \\
\hline $\mathrm{Chi}^{2} \mathrm{p}$-value & $<0.01$ & $<0.01$ & $<0.01$ & 0.02 \\
\hline
\end{tabular}

${ }_{-}=$Not applicable. CHFP $=$Navrongo Community Health and Family Planning Project. "In the comparison area, 1993-95 is treated as "preintervention" and 1996-2000 is treated as "intervention" time. 


\section{POLICY RESEARCH DIVISION WORKING PAPERS}

If still in print, single copies of up to three working papers from 1989 through 2003 are available free of charge.

Beginning with the 2004 issues, working papers are no longer available in print format. Instead they are distributed electronically. As each new paper is completed subscribers are notified by e-mail and a link to the paper is provided.

To subscribe to the Policy Research Division working paper e-mail notification list, or to obtain back issues from 1989 to 2003, please send your request to prdwp@popcouncil.org.

PDFs of recent issues are available at www.popcouncil.org/publications/wp/prd/rdwplist.html

2005

200 Brian Wells Pence, Philomena Nyarko, James F. Phillips, and Cornelius Debpuur, "The effect of community nurses and health volunteers on child mortality: The Navrongo Community Health and Family Planning Project."

199 Zachary Zimmer, Linda G. Martin, Mary Beth Ofstedal, and Yi-Li Chuang, "Education of adult children and mortality of their elderly parents in Taiwan."

198 Mian Bazle Hossain, James F. Phillips, and Thomas K. LeGrand, "The impact of childhood mortality on fertility in six rural thanas of Bangladesh."

197 Kristine R. Baker, Mary Beth Ofstedal, Zachary Zimmer, Zhe Tang, and Yi-Li Chuang, "Reciprocal effects of health and economic well-being among older adults in Taiwan and Beijing."

196 Mark R. Montgomery and Paul C. Hewett, "Poverty and children's schooling in urban and rural Senegal."

\section{4}

195 Luciana Suran, Sajeda Amin, Lopita Huq, and Kobita Chowdury, "Does dowry improve life for brides? A test of the bequest theory of dowry in rural Bangadesh."

194 Barbara S. Mensch, Monica J. Grant, Mary P. Sebastian, Paul C. Hewett, and Dale Huntington. "The effect of a livelihoods intervention in an urban slum in India: Do vocational counseling and training alter the attitudes and behavior of adolescent girls?"

193 Amanda Ritchie, Cynthia B. Lloyd, and Monica Grant. "Gender differences in time use among adolescents in developing countries: Implications of rising school enrollment rates."

192 John Bongaarts. "Long-range trends in adult mortality: Models and projection methods." 
191 John Koku Awoonor-Williams, Ellie S. Feinglass, Rachel Tobey, Maya N. Vaughan-Smith, Frank K. Nyonator, Tanya C. Jones, and James F. Phillips, "Bridging the gap between evidence-based innovation and national healthsector reform in Ghana."

190 Kelly Hallman, "Socioeconomic disadvantage and unsafe sexual behaviors among young women and men in South Africa."

189 Toshiko Kaneda, Zachary Zimmer, and Zhe Tang, "Differentials in life expectancy and active life expectancy by socioeconomic status among older adults in Beijing."

188 Cynthia B. Lloyd and Monica J. Grant, "Growing up in Pakistan: The separate experiences of males and females."

187 Zachary Zimmer, Xianghua Fang, Toshiko Kaneda, Zhe Tang, and Julia Kwong. "Trends and transitions in children's coresidence with older adults in Beijing municipality."

186 Sajeda Amin and Alaka M. Basu. "Popular perceptions of emerging influences on mortality and longevity in Bangladesh and West Bengal."

185 John Bongaarts. "Population aging and the rising cost of public pensions."
184 Mark R. Montgomery and Paul C. Hewett. "Urban poverty and health in developing countries: Household and neighborhood effects.

2003

183 Agnes R. Quisumbing and Kelly Hallman. "Marriage in transition: Evidence on age, education, and assets from six developing countries."

182 Paul C. Hewett, Barbara S. Mensch, and Annabel S. Erulkar, "Consistency in the reporting of sexual behavior among adolescent girls in Kenya: A comparison of interviewing methods."

181 Zachary Zimmer, Linda G. Martin, and Hui-Sheng Lin, "Determinants of old-age mortality in Taiwan."

180 Frank K. Nyonator, J. Koku Awoonor-Williams, James F. Phillips, Tanya C. Jones, and Robert A. Miller, "The Ghana Community-based Health Planning and Services Initiative: Fostering evidence-based organizational change and development in a resourceconstrained setting."

179 John Bongaarts and Griffith Feeney, "Estimating mean lifetime." 
178 Elizabeth F. Jackson, Patricia Akweongo, Evelyn Sakeah, Abraham Hodgson, Rofina Asuru, and James F. Phillips, "Women's denial of having experienced female genital cutting in northern Ghana: Explanatory factors and consequences for analysis of survey data."

177 John Bongaarts, "Completing the fertility transition in the developing world: The role of educational differences and fertility preferences."

176 Cynthia B. Lloyd and Paul C. Hewett, "Primary schooling in sub-Saharan Africa: Recent trends and current challenges."

175 James F. Phillips, Tanya C. Jones, Frank K. Nyonator, and Shruti Ravikumar, "Evidence-based development of health and family planning programs in Bangladesh and Ghana."

174 Geoffrey McNicoll, "Population and development: An introductory view."

173 Paul Demeny, "Population policy: A concise summary."

172 Zachary Zimmer, Napaporn Chayovan, Hui-Sheng Lin, and Josefina Natividad, "How indicators of socioeconomic status relate to physical functioning of older adults in three Asian societies."

171 Sajeda Amin and Nagah H. AlBassusi, "Wage work and marriage: Perspectives of Egyptian working women."
170 Ravai Marindo, Steve Pearson, and John B. Casterline, "Condom use and abstinence among unmarried young people in Zimbabwe: Which strategy, whose agenda?"

169 Zachary Zimmer and Julia Dayton, "The living arrangements of older adults in sub-Saharan Africa in a time of HIV/AIDS."

168 Paul C. Hewett, Annabel S. Erulkar, and Barbara S. Mensch, "The feasibility of computerassisted survey interviewing in Africa: Experience from two rural districts in Kenya." 